\title{
LEGISLATIVE AND OTHER MEASURES FOR THE TREATMENT OF THE INEBRIATE.*
}

\author{
BY T. CLAYE SHAW, M.D., F.R.C.P., \\ President of the Society for the Study of Inebriety ; \\ Lecturer on Psychological Medicine, St. Bartholomew's Hospital \\ Medical School.
}

THE word "drunkard," as far as my immediate purpose goes, implies the drinking of alcohol in some form to excess, and does not include drugging by hypodermic medication, inhalation, etc. Some people prefer the term "inebriate," because it is less opprobrious, and more comprehensive, and applies to both alcoholic inebriates and drug habitués; but it does not appear that there is any particular reason for sparing the feelings of those who indulge to excess. It so happens that a Departmental Committee of the Home Office is now sitting on this particular question. The scope of the inquiry is very large, and will, I understand, be extended to take evidence from many societies and individuals, including even some who are not recognized in medical circles as professional exponents of the subject. Not only has the British Medical Association itself been for some time actively concerned with the question now under consideration, but the Society for the Study of Inebriety, the Medico-Legal Society, the Medico-Psychological Association, and even the Turveyites, together with other bodies, are to lay their views before the Committee. I hope that some practical result will be arrived at by this section in the direction which the consensus of those most intimate with the facts seem to point to-viz., the necessity for the authority to use restraint

* Substance of an address introductory to a discussion before the Psychological Section of the British Medical Association, delivered at Sheffield, July 30, 1908. 
when it is required, and that the section's expression of opinion may be brought before the Committee as the deliberate conviction of a body of men who are intimately acquainted with the circumstances about which they are deliberating. I do not wish to discuss the medical treatment of the habitual drunkard, not because I believe medical treatment to be altogether a failure - on the contrary, the records of some of the inebriate homes where medical treatment is carried out might be quoted to prove the great value of remedies in some cases-but because they have already as much power as they want for the application of medical agencies. What we require is the possibility of obtaining a lengthened time during which remedies (if necessary) may be applied. A discussion on the most efficacious treatment of inebriety by drugs is well worth the attention of any society, but they are all probably agreed that, whilst the less legislative control there is over this strictly medical point the better (I am speaking now of properly qualified and registered practitioners), the time has arrived when, for the sake both of the patient and his social surroundings, it is necessary to have means at hand for the forcible control and detention of a person upon whom, whilst drugs have been tried and conspicuously failed, the curative elements of time and enforced abstinence from stimulants may have a reasonable chance of operating.

Section 3, Clause $3(b)$ of the Act reads as follows: " Habitual drunkard means a person who, not being amenable to any jurisdiction in lunacy, is notwithstanding, by reason of habitual drinking of intoxicating liquor, at times dangerous to self or others, or incapable of managing himself or his affairs." As practical men conversant with the various altered mental conditions in which acute or chronic inebriety shows itself, we all recognize that, whilst there are actual insanities produced by alcohol which require and are easily placed under certificates for asylum treatment, there are yet others which, though not certifiably insane, require compulsory sequestration for their own and others' safety. We also know that mental troubles caused by alcohol have a way of recovering in a most surprising manner when all alcohol is withdrawn, and that under the present state of the law it is not possible to detain these people, though we know that to discharge them is to invite a speedy return to the deplorable conditions which before existed; so that, if legislation is to be of real value, it must be both corrective and preventive.

Our interference is required for persons who drink to excess 


\section{The British Journal of Inebriety}

-perhaps constantly, perhaps intermittently-who, though rarely drunk in the sense that they are absolutely incapacitated, are yet unable adequately to discharge their obligations, who squander the money which should be for the family in racing, betting, and gambling, who pass much of their time in bed when they should be following their business, and who, through absence of definite delusions or hallucinations, cannot be certified as insane, who are ready to give promises of reformation which they do not keep, but who are always on dangerous ground, on the vortex of doing something which renders them liable to penal offences, though quite able to give plausible accounts of their conduct, and to sustain a certain amount of conversation on their actions. This is the condition where we want the law to help them, not only for the sake of the agent, but for those who are being slowly submerged and threatened with total extinction by a continuous current of banal excess, which should be dammed up or diverted. Why should this destructive, grinding, and oppressive creature be allowed to desolate his home, to endanger the good name of his wife and children, and to pauperize his dependents, who ought to have the means of staying the destruction which they can see is gradually overtaking them. At present the law takes no notice of acts unless they actually cause harm to self or others, not of continued evil practices which may do harm. There is apparently nothing to prevent an inebriate acquiring a licence to carry firearms and buying a revolver, as long as he neither threatens to nor actually uses it; only when he has used it does he come within the clutch of the law, though all the time he is in such a condition that the impulse to use it may arise at any moment, and the mischief be done before it could be prevented. Is such a possibility right either for the man himself or for society in general ?

I come now to the legal processes which should be invoked, remarking, in the first place, that there is a dual control-viz., that of the Secretary of State, who regulates the management of the retreat and the duties of inspection, and the County and Borough Councils which are the authorities for the granting of licences. I am able to state that the experience of those versed in the working of these retreats is, that this dual control is for many practical reasons, unsatisfactory, and that to the Secretary of State alone should be committed the power to grant, transfer, or withhold licences, and, moreover, that compulsory licensing of all retreats should be made absolute. 
The question has been raised whether it would be of advantage to grant licences to lunatic asylums for the reception of habitual drunkards. I beg to suggest that it would, for the following reasons: In a paper read before the Medico-Legal Society on December 17, 1907, I remarked that when a person insane from alcohol has been placed in an asylum, and has so rapidly recovered that he can no longer be detained, it should be possible for the governing authorities to discharge the patient for a term of probation to an inebriate home, the term to be capable of extension as long as is considered necessary. I still think that removal to the home would be a good thing for the well-to-do person who may have been placed during his attack of insanity in a private asylum; but in the case of the pauper patient the advantage of removing him to the part of the asylum licensed for the reception of inebriates would be a cheap and expeditious way of keeping him under supervision, whilst it would free him from the company of actually insane persons, and it would prevent the stress put upon the accommodation at existing inebriates homes, and the expense would be lessened.

For a private patient whom it is not expedient or even possible to confine in an asylum, I would have the powers granted to place him in a home upon the authority of two medical certificates, somewhat similar in form to lunacy certificates, but free from certain objectionable phrases which existed in the latter. These certificates should be available for at least six months, and should be capable of renewal for additional terms of six months if considered necessary by the authorities of the home. Whilst under these certificates the patient would be allowed to transact such business as he was deemed capable of by the home authorities and their Superintendent. But special permission would have to be given for these acts of responsibility, and during the time of his detention all personal liberty would be denied except by special permission of the Superintendent. A question arises as to the propriety of having the order of commitment to the home signed by the next of kin. It would probably be better for the future family harmony if the immediate members could be kept clear frnm unpleasant participation in the detention of the head of the bouse; but, on the whole, it is probably only right that the friends must undertake some responsibility, and therefore it may be concluded that some authorization from a near relative must accompany the certificates, either as a separate document or conjointly with those of the 
certifying doctors. The advisability of having the order of a magistrate is also a debatable point. Experience of certification in lunacy cases is not entirely in favour of having a magistrate's order, for in urgency cases it is not in the first instance required. If the order of the magistrate is understood to be nothing more than a formal official cachet that a certain process has been complied with, there would appear to be no reason, beyond the question of delay, why it should not be made compulsorily; but if it is to involve discretionary power, then the possible harm of requiring it is apparent, because the arbiter is not always in a position to adjudge the validity of the premises.

The patient thus compulsorily secluded ought to have safeguards. Whilst under detention he would be visited by the Government inspectors, and he would have his legal remedies for improper certification, just as the lunatic now has.

I note that the Departmental Committee on the Inebriates Act has issued a series of questions for the guidance of witnesses submitting evidence before it. And from the scope of these questions it is evident that the whole subject of new legislation in regard to the taxation and licensing of retreats, the compulsory certification and seclusion of habitual drunkards, or inebriates, their employment and treatment when in retreats, etc., is to receive the fullest consideration. But I venture to suggest, with their permission, that a resolution embodying the views of this section of the British Medical Association on the question of the urgency of compulsory legislation in the cases under consideration might be presented to the Council with a view to its being brought before the notice of the Departmental Committee with the object of re-enforcing such testimony as is brought before it in favour of this proceeding. Section D of the "Questions" 8ays: "In view of the fact that 1879 Act only empowers the detention of inebriates when they themselves desire treatment, and the 1898 Act only when the inebriate becomes criminal or degraded, are you of opinion that further powers are necessary to authorize the treatment, guardianship, or detention of inebriates who cannot be controlled or treated under any existing power ?" Surely our answer could only be that we do think so, and that whether the means employed be by certification, or by inquiry on commission (as has been urged by one very experienced prison physician), we must do all in our power to back up such efforts as are being made to attain this end. I conclude by vOL. VI. 


\section{The British Journal of Inebriety}

saying that we can teach people the necessity for moderation; but alcohol is always a dangerous instrument, and we cannot be surprised if some who do not know how to use it as a servant find that it becomes a tyrannous master. Drunkenness may not be the end for which alcohol is taken, but the social system which permits the insidious ensnarement, welling up finally in a paralyzing incompetence for economic duties, should also provide the means of escape from the net if, even, by temporary restraint of another kind; and it should resolve that the possession of such a power is not a futile asset. There is really nothing novel in legislating to effect the compulsory detention and control of these persons, except that this country already lags behind numbers of others, whilst in some places ( $I$ am now quoting from particulars furnished by Dr. Hogg, of the Dalrymple Home, Rickmansworth) still more stringent laws are in action, because an habitual drunkard who is obliged to seek help from the authorities to support himself or his family is liable to arrest, and may be placed in a workhouse for a term not exceeding two years,

To carry out with all due safeguards the measures above proposed is not asking too much in the way of public expenditure, because the private patients will be able to pay, and if the present homes for pauper inebriates are not sufficient, it will be possible to make use of the machinery of the present county asylums by adding a little to their accommodation. 